Journal of the Experimental ANAlysis of Behavior 1984-1993

\title{
GUMULATIVE INDEX
}

\author{
Volumes 41-60 \\ 1984-1993 \\ HOW TO USE THE INDEX
}

The Cumulative Index consists of four sections:

1. Author Index. Entries include regular articles, special articles, book reviews, and technical articles and notes published in this journal, arranged alphabetically by author. Cross-references to co-authored papers for which the particular author was not first author are grouped together at the end of the alphabetical listing for that author.

2. Subject Index. Entries are based on all articles published in this journal. For experimental subjects (e.g., rat), indexing is limited primarily to those studies concerned with a species-specific problem or with an interspecies comparison, or if subjects other than pigeons, rats, or monkeys were used.

3. Tables of Contents. In each of the above indexes, articles in this journal are cited by volume number and page: e.g., $(41,35)$ represents Volume 41, page 35. The author(s) and title for such a citation may be located without leaving the Cumulative Index by consulting the Tables of Contents, in which articles are arranged by volume and page number.

4. Book Reviews. For the reader's convenience, titles have been repeated in this separate listing. 